(C) Basil Blackwell Itd. 1995, 108 Cowley Road, Oxford OX4 IJF, UK and 238 Main Street, Suite 501, Cambridge MA 02142, USA.

Ratio (New Series) VIII I April $19950034-0006$

\title{
DISGUSSION
}

\section{TRUTH WRONGED: CRISPIN WRIGHT'S TRUTH AND OBJECTIVITY}

\section{Ian Rumfitt}

This book reproduces, with some supplements and revisions, the content of Professor Wright's Waynflete Lectures, delivered at Oxford in 1991. Although their literary style could not be described as conversational, there are other respects in which the book betrays its origin. Especially in the earlier chapters, there is little actual citation or close discussion of writings by other philosophers, even when Wright is locating his own position in part by reference to their theories; moreover, as the preface readily concedes, many questions are left undecided. More worrying, perhaps, is a certain sketchiness in many of the arguments: some concepts central to those arguments nowhere receive the detailed analysis that would be needed for full argumentative explicitness. As I think the discussion below will show, this is certainly true of Wright's treatment of assertion.

The book's aim is to consider - or to reconsider - the manner in which debates between 'realists' and 'anti-realists' over various disciplines might best be conducted. However, although Wright alludes to such debates - for example, over realism in ethics and in the philosophy of mathematics - little space is devoted to their details, and the book soars serenely at a pretty stratospheric level of generality, for the most part untroubled by the turbulence created by specific disputes. Readers who are not antecedently convinced that there are important 'family resemblances' between such debates should be warned that they may find utterly alien the book's very point of departure.

In relation to its aim, the book divides naturally into two unequal parts. In the first, which is complete by the middle of the third chapter, Wright attempts to re-orient debates about realism so that they focus less upon the question whether the utterances of a given discipline are susceptible of assessment as true or as false. Indeed, it is said, when the predicate 'true' is properly understood, this question emerges as having little interest: it will be reasonably uncontroversial that moral utterances, utterances about what is funny, \&c., are apt to be true or false. In Wright's own words, then 
'truth [or falsity] need not be the exclusive property of realism' (p. 12). In the second and longer part, Wright explores a number of concepts in whose terms the debate about realism might instead proceed. Centrally, he discusses the notions:

(1) of cognitive command: which a 'discourse' will exhibit just when it is a priori that differences of opinion between participants can be explained only by positing some cognitive shortcoming (whether of ignorance, inattention, or prejudice) on the part of at least one of them (pp. 92-93);

(2) of detectivism: which a discourse will exhibit if the best judgements made by its participants track facts in rebus. Such a discourse is to be contrasted with one in which the best judgements of its participants constitute the truth grounds of its claims (cfr. esp. pp. 79-80);

(3) of width of cosmological role: which a discourse exhibits to the degree that its judgements explain things other than - or other than via - subjects' being in the attitudinal states expressed by such judgements.

Realism about a discourse, then, is vindicated to the degree that it exhibits cognitive command, is detectivist, and displays a wide cosmological role.

Interesting as are many of the reflections in this second part, their exploratory nature makes them comparatively resistant to quick summary and assessment. Accordingly, I shall devote the remainder of this notice to the main arguments of the first part of the book, i.e. to Wright's views about truth, and aptness for assessment as true or as false.

Wright begins his discussion of truth by attempting to refute the account of it that he calls deflationary, and which he characterizes by the following two theses (formulated most explicitly on p. 30):

(a) that 'true' functions purely as a device for endorsing assertions, beliefs and so on ... and which therefore registers no norm distinct from justified endorsability - that is, assertibility;

(b) that the disquotational schema [viz. the schema ' $p$ ' is true if and only if $p$ ] constitutes a complete explanation of the meaning of the word 'true'.

(The notion of 'registering a norm' is left somewhat obscure, but I suppose that a predicate $\mathrm{P}$ registers a norm $\mathrm{N}$ just when $\mathrm{N}$ lays

(C) Basil Blackwell Ltd. 1995 
down some rule which guides the application of $P$.) The contention of (a), then, is that the only norm constraining the application of the truth predicate to a sentence is whichever norm constrains the assertibility of the sentence itself.

Wright undertakes to show that these two elements are incoherent whenever a discourse admits neutral states of information - i.e. states of information which, for some sentence in the discourse, warrant neither its assertion nor its denial. For the disquotational schema yields:

'It is not the case that $p$ ' is true if and only if it is not the case that $\mathrm{p}$

and also (given an unexceptionable logical principle):

It is not the case that $p$ if and only if it is not the case that ' $p$ ' is true

and these together deliver:

'It is not the case that $p$ ' is true if and only if it is not the case that ' $p$ ' is true.

But if ' $p$ ' is a sentence for which a state of information is neutral, 'it is not the case that p' will be unwarranted even though 'p' is not warranted. Accordingly, in any such case the extension of 'is true' demonstrably diverges from the extension of 'is warranted'. We are, then, "forced to recognize that while "is [true]" and "is warrantedly assertible" are normatively coincident, satisfaction of the one norm does not entail satisfaction of the other' (p. 21). This is presented as 'a fundamental and decisive objection to deflationism as classically conceived' (ibid.).

This claim, however, is surely grossly inflated. Wright's deflationist is struck (quite justly) by the likeness exhibited by the norms which regulate the application of the predicates 'is true' and 'is warrantedly assertible'. Indeed, the likeness extends to both positive and negative norms in Wright's sense (cf. p. 15) so that we have

The predicate 'is true' may be applied to any sentence for which one has a warrant

standing alongside

The predicate 'is warrantedly assertible' may be applied to any sentence for which one has a warrant; 
and

The predicate 'is true' may not be applied to any sentence for which one lacks a warrant

standing alongside

The predicate 'is warrantedly assertible' may not be applied to any sentence for which one lacks a warrant.

Now the divergence to which Wright draws attention arises because this parallel does not extend to the norms which regulate application of the negations of these predicates. So, while we have:

The predicate 'is not warrantedly assertible' may be applied to any sentence for which one lacks a warrant,

we don't have:

The predicate 'is not true' may be applied to any sentence for which one lacks a warrant.

It is, however, hard to see why Wright takes this to be a deep problem for the deflationary conception of truth. For cognate to the notion of affirming something is the notion of denying it; and cognate to the notion of having a warrant for affirming something is the notion of having a warrant for denying it (or, for brevity, having an anti-warrant). And, with these cognate notions in play, it is straightforward to formulate the norm which does regulate the application of 'is not true', viz.

The predicate 'is not true' may be applied to any sentence for which one possesses an anti-warrant.

Indeed, this norm is needed to account for the universal assertibility of the disquotational biconditionals, for a sentence's negation is also assertible just when one possesses an anti-warrant for it. To be sure, clause (a) of Wright's characterization of deflationism needs to be emended so that it reads:

$\left(a^{\prime}\right)$ that 'is true' and 'is not true' function purely as devices for endorsing and rejecting assertions, beliefs and so on ... and which therefore register no norms distinct from justified assertibility and justified deniability.

However, such an emendation seems entirely in the spirit of deflationary views; certainly, we remain far from the 'metaphysically substantial' notions of truth at which the deflationist characteristically balks.

(C) Basil Blackwell I.td. 1995 
Of greater moment, however, is Wright's own account of the truth predicate, for it is this that underpins his contention that truth need not be the exclusive property of realism. Wright recommends a 'kind of minimalism about truth ... The minimalist view is that when a predicate has been shown to have the relevant features, and to have them for the right reasons, there is no further question about the propriety of regarding it as a truth predicate. Minimalism is thus in principle open to the possibility of a pluralist view of truth: there may be a variety of notions, operating within distinct discourses, which pass the test' (pp. 24-25). The 'features' in question are that a truth predicate conforms to the disquotational schema, and that its extension potentially diverges from that of a warranted assertibility predicate. And a predicate will possess these features for the right reason if the features in some way derive from a number of basic 'platitudes' which Wright takes to be fundamentally constitutive of truth: for example, the platitude that to assert a proposition is to claim that it is true (p. 24).

It is this conception that underlies Wright's approach to the question of which discourses are composed of utterances susceptible of assessment as true or false - i.e. (in Wright's handy if unlovely phrase) of which discourses are truth-apt. 'My suggestion', he writes, 'is that since any predicate should be accounted a truth predicate which has just the features highlighted by minimalism, any discourse may count as truth-apt on which it is possible to define a predicate with just those features. And the condition for the definability of such a predicate is merely that the discourse be one of assertion, that its utterances be governed by norms of warranted assertibility' (pp. 27-28). However, as Wright clearly sees (p. 28), this by itself does not show that an anti-realist about a discourse ought to be insouciant about conceding its truth-aptness. Rather, what he needs to show in addition is that the anti-realist should be insouciant about conceding that the discourse in question is assertoric.

His attempt to demonstrate this has an appealing directness:

there is no notion of genuine - deep - assertoric content, such that a discourse which exhibits whatever degree of discipline (there are firmly acknowledged standards of proper and improper use of its ingredient sentences) and which has all the overt syntactic trappings of assertoric content (resources for - apparent - conditionalization, negation, embedding within propositional attitudes and so on) - no notion of genuine assertion such that a 
discourse with all this may nevertheless fail to be in the business of expressing genuine assertions. Rather, if things are in all these surface aspects as if assertions are being made, then so they are (p. 29).

But, direct as it may be, this claim strikes me as quite indefensible.

There is, to be sure, some indeterminacy in what the claim actually amounts to, indeterminacy which stems from unclarity in the notion of a discourse. It would certainly be uncharitable to attribute to Wright the claim that any 'disciplined' utterance of any sentence of some appropriate syntactic kind qualifies as an assertion: the pronouncements of utterances on the stage are paradigms of non-assertive utterance and yet it is open to a playwright to put sentences of any syntactic form into the mouths of his characters. This shows, I take it, that utterances on the stage do not constitute a 'discourse' in Wright's sense; and we might speculate that those who participate in a discourse must do so with an earnestness lacking in actors on a stage.

Even setting to one side the considerable problem of explicating the relevant notion of earnestness, other grounds for doubting Wright's claim crowd in. It is, for example, notoriously hard to construct a syntactic criterion which distinguishes those utterances which Austin liked to call performatives from those he designated constatives. Moreover, many of them are tightly disciplined in Wright's sense: there are 'firmly acknowledged standards of proper and improper use' of the sentences used in declaring war, making bets, launching ships, marrying somebody, \&c. \&c. And yet, whatever we make of Austin's denial that performatives are truthapt, he was surely right to deny that such performatives are assertions, and that the sentences used in making them are assertoric. An utterance qualifies as an assertion only if it may be reported in the style 'The speaker asserted, or claimed, that suchand-such is this case'; but it is hard to see what report in this style could truly be made of 'We declare war on Germany', 'I bet you sixpence that it will not rain' or 'I name this ship the Queen Elizabeth'. Furthermore, there are examples which create difficulties in the other direction. A debate rages, for instance, over whether utterances of vernacular conditionals constitute assertions. However, vernaculars differ from formal languages in resisting the nested embedding of conditionals. Even so simple a case as 'If if it rains then the match will be cancelled then the rules of the cricket club are being misapplied' is not a sentence of English, so that

(C) Basil Blackwell Ltd. 1995 
conditionals fail to display one of Wright's 'overt syntactic trappings of assertoric content'. I take it, though, that few will be prepared to conclude just on that ground that they are not assertoric.

It may, however, be replied to all of this that Wright's direct claim about assertion goes beyond what he really needs. Some philosophers, after all, have been prepared to ascribe conditions of truth and falsity to ironical remarks, jokes, and other utterances that we should not normally regard as assertive. Given, then, that this is at least an open possibility, Wright need not claim that various discourses are uncontroversially assertoric in order to sustain his main contention, that they are uncontroversially truthapt. We might ask, then, after the prospects of an argument to this conclusion which side-steps any consideration of the nature of assertion.

Such prospects, I fear, are dim. Wright himself plausibly requires that a truth-apt sentence yield an instance of the disquotational schema: if ' $p$ ' is apt for assessment as true or false, then there must be conditions under which it is true and/or conditions under which it is false, and as a statement of those conditions we can hardly hope to improve upon

' $p$ ' is true if and only if $p$.

But, even leaving aside the obvious problem over whether an instance of this schema can be true if ' $p$ ' fails to be truth-apt, there are problems over its assertibility. For when is a vernacular biconditional assertible? Presumably, when both of its component conditionals are assertible. Yet (on the most plausible view of the matter) a vernacular conditional is assertible to the degree that one is prepared to assert the consequent, given a preparedness to assert the antecedent. But then, as it seems, there is no hope after all of avoiding engagement with the issue, whether it makes sense to speak of asserting that $p$.

The significance of this problem for Wright's general project can hardly be overestimated. A plausible view of assertion (essentially Frege's view) takes utterances to be assertive just when they purport to express beliefs: accordingly, a type sentence will be assertoric only when it is apt for the expression of a belief. But whether the putatively assertoric sentences of a discourse qualify as expressive of beliefs is a deep question over which a realist and an anti-realist will typically disagree. Indeed, spelling out what is at issue between them here will typically involve a number of the

(C) Basil Blackwell L.td. 1995 
notions to whose elucidation Wright devotes the second part of his book. But in that case aptness for truth or falsity has not after all been dislodged as a litmus test for realism. And Wright has not shown that truth need not be the exclusive property of realism.

Department of Philosophy, The University of Michigan, Ann Arbor, Michigan 48109-1432

$U S A$ 